\title{
Isolation and Expansion of Mesenchymal Stem Cells from Murine Adipose Tissue
}

Natalia V. Andreeva ${ }^{1}$, Alexandra A. Dalina ${ }^{2}$ and Alexander V. Belyavsky ${ }^{1, *}$

\author{
${ }^{1}$ Laboratory of Stem and Progenitor Cell Biology, Engelhardt Institute of Molecular Biology, Russian \\ Academy of Sciences, Moscow, Russia; ${ }^{2}$ Laboratory of Cell Proliferation, Engelhardt Institute of \\ Molecular Biology, Russian Academy of Sciences, Moscow, Russia \\ *For correspondence: abelyavs@yahoo.com
}

\begin{abstract}
[Abstract] Mesenchymal stem cells (MSCs) are currently intensively studied due to significant promise which they represent for successful implementations of future cell therapy clinical protocols. This in turn emphasizes importance of careful preclinical studies of MSC effects in various murine disease models. The appropriate cell preparations with reproducible biological properties are important to minimize variability of results of experimental cell therapies. We describe here a simple protocol for isolation of murine MSCs from adipose tissues and their reproducible multi-log expansion under hypoxia conditions.
\end{abstract}

Keywords: Mesenchymal stem cells, Adipose tissue, Oxidative stress, Hypoxia, Expansion

[Background] MSCs were identified initially by Friedenstein as cells in bone marrow with fibroblast-like morphology, adherence to the plastic and high self-renewal capacity resulting in formation of fibroblastlike colonies in vitro (Friedenstein et al., 1976; reviewed in Phinney and Sensebé, 2013). The MSCs, due to their potential applications in medicine, are currently one of the most intensively studied adult progenitor cell types. These cells can be isolated from various organs (Murray et al., 2014), and are thought to originate from the blood vessels, either as pericytes or as vessel wall cells. In addition to their capacity to differentiate along osteogenic, adipogenic and chondrogenic lineages, MSCs possess immunomodulating properties and are thought to participate in responses to tissue damage as well as to orchestrate anti-inflammatory reactions through their ability to influence macrophage polarization (Prockop, 2013; Caplan, 2016).

Given these properties, MSCs represent significant promise for successful implementations of future relevant cell therapy clinical protocols. This in turn emphasizes importance of careful preclinical studies with MSCs in various murine disease models. The ability to prepare large numbers of appropriate cell samples with reproducible biological properties is of vital importance for minimization of variability of results during development of MSC-based experimental cell therapies. However, unlike human MSCs that possess strong anti-oxidative defenses and thus grow fairly well under atmospheric oxygen conditions, mouse MSCs are much more sensitive to oxygen stress and have a limited lifespan and expansion capacity when cultured in conventional $\mathrm{CO}_{2}$ incubators. Culturing these cells under hypoxic conditions, on the contrary, significantly extends their lifespan and allows for multi-log expansion, providing sufficient amounts of cell material with reproducible properties for repeated experiments with murine experimental disease models (Boregowda et al., 2012; Krishnappa et al., 2013). In the present 
paper, we describe a simple protocol for isolation of murine MSCs from adipose tissue, their reproducible expansion under hypoxia conditions, as well as long-term storage.

\section{Materials and Reagents}

1. $6 \mathrm{~cm}$ cell culture dish (Greiner Bio One International, catalog number: 628160 )

2. Sterile pipette filter tips $20 \mu \mathrm{l}$ (Greiner Bio One International, catalog numbers: 774288)

3. Sterile pipette filter tips $200 \mu \mathrm{l}$ (Greiner Bio One International, catalog numbers: 739288)

4. Sterile pipette filter tips $1,000 \mu \mathrm{l}$ (Greiner Bio One International, catalog numbers: 740288)

5. $15 \mathrm{ml}$ centrifuge tube (Greiner Bio One International, catalog number: 188261)

6. $50 \mathrm{ml}$ centrifuge tube (Greiner Bio One International, catalog number: 227261)

7. $1.8 \mathrm{ml}$ round bottom cryogenic tubes (Thermo Fisher Scientific, Thermo Scientific ${ }^{\mathrm{TM}}$, catalog number: 375418)

8. $10 \mathrm{~cm}$ cell culture dish (Greiner Bio One International, catalog number: 664160)

9. $3.5 \mathrm{~cm}$ cell culture dish (Greiner Bio One International, catalog number: 627160 )

10. Cotton wool

11. Vacuum filter/storage bottle system, $0.22 \mu \mathrm{m}, 500 \mathrm{ml}$ (Corning, catalog number: 431097)

12. $0.22 \mu \mathrm{m}$ syringe filter (Sigma-Aldrich, catalog number: Z741948)

Manufacturer: GVS, catalog number: 1214220.

13. $10 \mathrm{ml}$ syringe (SFM Hospital Products, catalog number: 534235$)$

14. $2 \mathrm{ml}$ serological pipets (Greiner Bio One International, catalog numbers: 710180)

15. $5 \mathrm{ml}$ serological pipets (Greiner Bio One International, catalog numbers: 606180)

16. $10 \mathrm{ml}$ serological pipets (Greiner Bio One International, catalog numbers: 607107)

17. $25 \mathrm{ml}$ serological pipets (Greiner Bio One International, catalog numbers: 760160)

18. C57BL/6 mice

19. Sterile distilled water

20. Ethanol 96\% (Sigma-Aldrich, catalog number: 24105)

Note: This product has been discontinued.

21. Trypan blue solution, $0.4 \%$ (Thermo Fisher Scientific, Gibco ${ }^{\mathrm{TM}}$, catalog number: 15250061)

22. Dimethyl sulfoxice (DMSO) (Sigma-Aldrich, catalog number: D2650)

23. Propidium iodide (PI) (Thermo Fisher Scientific, Invitrogen ${ }^{\mathrm{TM}}$, catalog number: P3566)

24. Cell culture media components

a. DMEM low glucose, powder (Thermo Fisher Scientific, Gibco ${ }^{\mathrm{TM}}$, catalog number: 31600083 )

b. GlutaMax (100x) (Thermo Fisher Scientific, catalog number: 35050038)

c. Penicillin-streptomycin (100x) (Thermo Fisher Scientific, Gibco ${ }^{\mathrm{TM}}$, catalog number: 15140122)

d. Sodium hydrogen carbonate cell culture grade (AppliChem, catalog number: A0384)

25. Amphotericin B $(0.25 \mathrm{mg} / \mathrm{ml})$ (Thermo Fisher Scientific, Gibco ${ }^{\mathrm{TM}}$, catalog number: 15290018$)$

26. Collagenase from Clostridium histolyticum (Sigma-Aldrich, catalog number: C2674) 
27. Fetal bovine serum (GE Healthcare, HyClone ${ }^{\mathrm{TM}}$, catalog number: $\mathrm{SV} 30160.03$ )

28. Phosphate-buffered saline (PBS), pH 7.4 tablets (Thermo Fisher Scientific, catalog number: 18912014)

29. Trypsin from porcine pancreas (Sigma-Aldrich, catalog number: T4799)

30. Ethylenediaminetetraacetic acid disodium salt (EDTA) (Sigma-Aldrich, catalog number: E5134)

31. DMEM low glucose medium (see Recipes)

32. MSC isolation medium (see Recipes)

33. Collagenase solution (see Recipes)

34. MSC growth medium (see Recipes)

35. 1x phosphate-buffered saline (PBS) pH 7.4 (see Recipes)

36. Trypsin solution (see Recipes)

\section{Equipment}

1. Sterilized surgical tools including forceps and scissors

2. Pipette controller (Corning, catalog number: 4091)

3. Automatic single-channel pipettes, $0.5-20,20-200$ and 100-1,000 $\mu \mathrm{l}$, Gilson-compatible (Gilson)

4. Analytical balance*

5. Thermostated shaker (Eppendorf, New Brunswick ${ }^{T M}$, model: Innova ${ }^{\circledR} 4000$ )

Note: This item has been discontinued. Possible substitute: Eppendorf, New Brunswick ${ }^{T M}$, model: Innova ${ }^{\circledR} 40$.

6. Centrifuge $5810 \mathrm{R}$ (Eppendorf, model: $5810 \mathrm{R}$, catalog number: 5811000320 )

7. Multigas incubator (SANYO, model: MCO-19M)

Note: This item has been discontinued. Possible substitute: Panasonic Healthcare, model: MCO-170M.

8. Laminar flow tissue culture hood*

9. Inverted microscope*

10. Hemocytometer*

11. Refrigerator*

12. Ultra-low temperature freezer (Panasonic Healthcare, catalog number: MDF-U3386S)

13. Locator 6 Plus Rack and Box Systems, liquid nitrogen tank (Thermo Fisher Scientific, Thermo Scientific ${ }^{\top M}$, catalog number: CY50985-70)

14. Autoclave*

*Note: This item can be ordered from any qualified company. 


\section{Procedure}

A. Isolation of murine MSCs

Note: Perform all manipulations under sterile conditions. In order to keep digestion conditions reproducible between subsequent cell isolations, the volumes of solutions during the crucial collagenase digestion step are determined based on the weight of adipose tissue.

1. Sacrifice mice by cervical dislocation. Sterilize animals by submerging into $70 \%$ ethanol for 5 $10 \mathrm{~min}$.

Note: Mice may also be euthanized by $\mathrm{CO}_{2}$ inhalation or other approved methods. The number of animals used for isolation depends on the set goals. Given the high expansion capacity of MSCs, one to two animals would suffice for most applications.

2. Dissect the abdominal skin to expose subcutaneous adipose tissue (Video 1).

\section{Video 1. Mouse dissection}

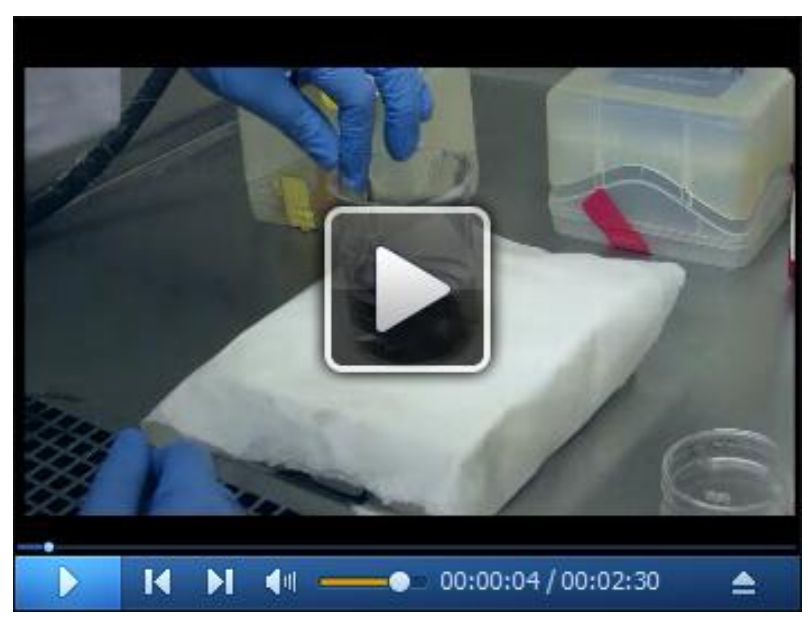

3. Extract the subcutaneous adipose tissue using sterile forceps and scissors (Video 2).

Video 2. Excision of adipose tissue

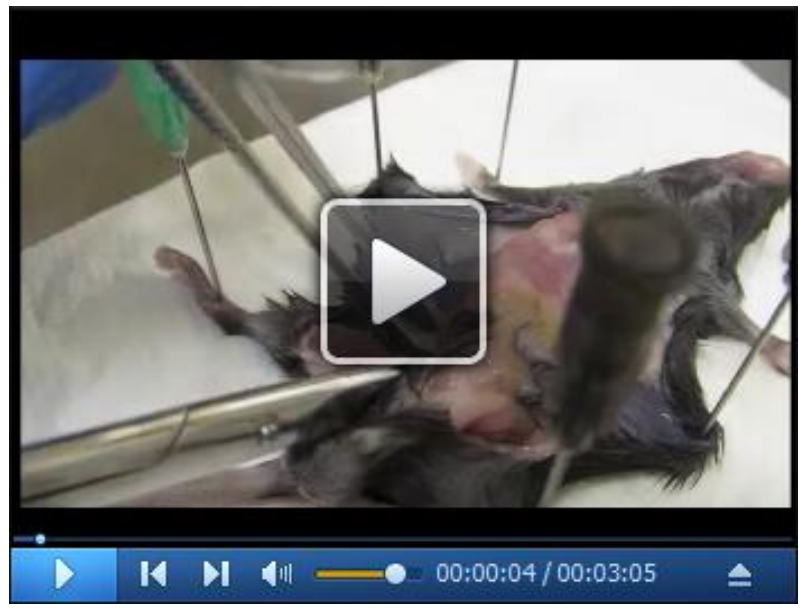


4. Place the extracted tissue to a pre-weighted 6-cm Petri dish. Measure the weight of extracted tissue $(\mathrm{N} \mathrm{g})$ using an analytical balance.

5. Add $1 \times \mathrm{N} \mathrm{ml}$ (where $\mathrm{N}$ is the weight of adipose tissue in grams) of the room temperature MSC isolation medium (see Recipes) to the Petri dish containing adipose tissue.

Note: Although adipose tissue can stay for some time in MSC isolation medium until collagenase solution (see Recipes) for tissue dissociation is added, it is recommended to recruit an assistant solely for this step, whose task would be to prepare the collagenase solution once the weight of extracted adipose tissue is determined.

6. Mince adipose tissue with sterile scissors until a fine-pieced slurry is formed (Video 3).

Video 3. Mincing of adipose tissue

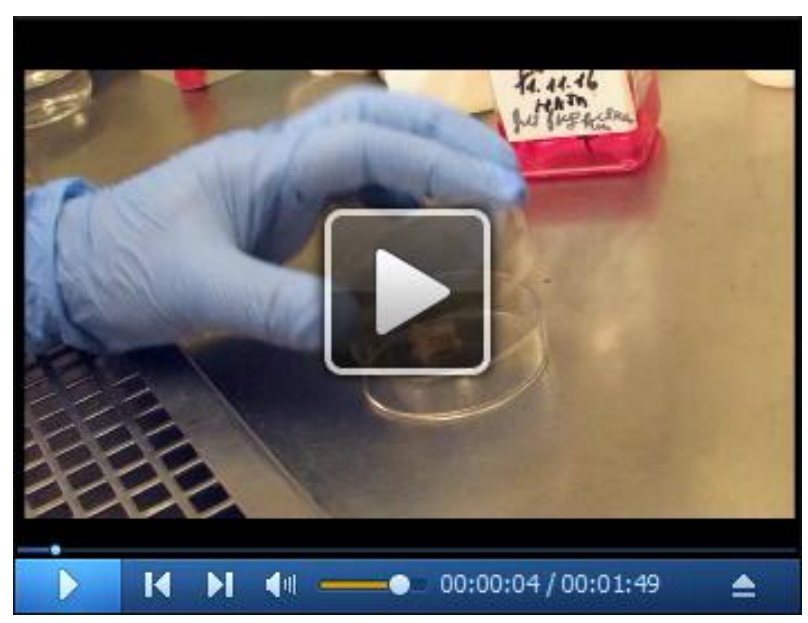

7. Using a 1-ml filter tip with the cut-off end, transfer accurately the minced tissue to a 15-ml centrifuge tube (Video 3).

Note: If the weight of adipose tissue exceeds $2 \mathrm{~g}$, use a $50-\mathrm{ml}$ centrifuge tube instead.

8. Add $2.5 \times \mathrm{N} \mathrm{ml}$ of MSC isolation medium to the Petri dish, wash and transfer the remaining pieces of tissue to the same 15-ml tube.

9. Add $0.5 \times \mathrm{N} \mathrm{ml}$ of the prepared collagenase solution to the tube with the minced tissue (Video 3).

10. Incubate for $40 \mathrm{~min}$ at $37^{\circ} \mathrm{C}$ with constant agitation in a thermostated shaker at a speed of 200 RPM (Video 4). 


\section{Video 4. Treatment with collagenase and centrifugation}

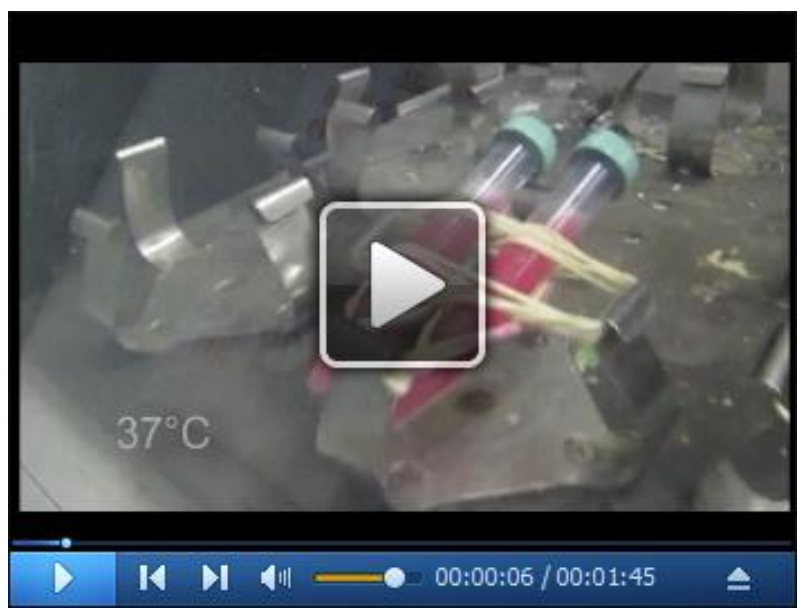

11. Pipette up and down the resulting cell suspension 20-30 times using a $10 \mathrm{ml}$ pipette until homogeneous.

12. Centrifuge cell suspension at $22^{\circ} \mathrm{C}$ for $10 \mathrm{~min}$ at $370 \times g$ (Video 4 ).

13. Discard the supernatant, add $1 \mathrm{ml}$ of MSC isolation medium and resuspend cells using a 1-ml filter tip. Add $9 \mathrm{ml}$ of MSC isolation medium, mix and centrifuge at $22^{\circ} \mathrm{C}$ for $10 \mathrm{~min}$ at $370 \times \mathrm{g}$ (Video 4).

14. Repeat the step A12 once more. Resuspend cells in $1 \mathrm{ml}$ of MSC growth medium (see Recipes).

15. Count the total number of isolated cells using hemocytometer.

Note: The average number of isolated cells at this stage is variable but usually about 5-15 million cells per mouse.

16. Seed 5 to 7 million cells per $10-\mathrm{cm}$ Petri dish, add MSC growth medium to each dish to a final volume of $10 \mathrm{ml}$, and cultivate at $37^{\circ} \mathrm{C}$ in a $\mathrm{CO}_{2}$ incubator under hypoxic conditions $\left(5 \% \mathrm{CO}_{2}\right.$, $5 \% \mathrm{O}_{2}$ ) (Video 4).

Note: When adding MSC growth medium, aim to spread cells evenly throughout the dish by tilting it and/or using pipet.

17. Culture passage zero cells for 5-7 days up to $70-80 \%$ confluency, with MSC growth medium changes after the first day and every 3 days afterwards. The cells at this stage have a slightly elongated fibroblast-like shape.

18. Tilt the Petri dish and carefully aspirate the culture medium from the plastic-attached cells avoiding their disturbance and detachment, wash once with 1x PBS (see Recipes).

19. Add $1 \mathrm{ml}$ of trypsin solution (see Recipes) to each $10-\mathrm{cm}$ Petri dish, detach cells at $37^{\circ} \mathrm{C}$ for 5 $10 \mathrm{~min}$.

Note: Monitor the degree of cell detachment microscopically after 5 min of incubation; if necessary, extend incubation until the vast majority of cells are detached, but not longer than 10 min (see Note 3).

20. Transfer cells to a 15- $\mathrm{ml}$ centrifuge tube, add $5 \mathrm{ml}$ of MSC growth medium, mix by gentle pipetting and centrifuge at room temperature for $7 \mathrm{~min}$ at $370 \mathrm{xg}$. 
21. Suspend cells in 1-2 $\mathrm{ml}$ of MSC growth medium.

22. Mix a cell aliquot with an equal volume of trypan blue solution and count live cells using hemocytometer.

B. Expansion of murine MSCs

Note: Perform all manipulations under sterile conditions.

1. Seed the MSC cell suspension into appropriate culture vessels at a density of 200 to 400 cells $/ \mathrm{cm}^{2}$.

2. Culture cells in $\mathrm{MSC}$ growth medium for 3 to 4 days in a $\mathrm{CO}_{2}$ incubator under hypoxic conditions $\left(5 \% \mathrm{CO}_{2}, 5 \% \mathrm{O}_{2}\right)$ until reaching $50 \%$ to $70 \%$ confluency. Change medium every 3 days. Notes:

a. The effect of hypoxic conditions on murine MSC growth is illustrated in the Figure 1.

b. The optimal culture time depends on seeding density: for $200 \mathrm{cells} / \mathrm{cm}^{2}$ the optimal culture time is usually 4 days, whereas for 400 cells $/ \mathrm{cm}^{2}-3$ days.

3. Detach cells with trypsin and count them analogously to the steps A16-A20 of the Procedure A above.

4. Repeat steps B1-B3 until the required number of MSC is obtained.

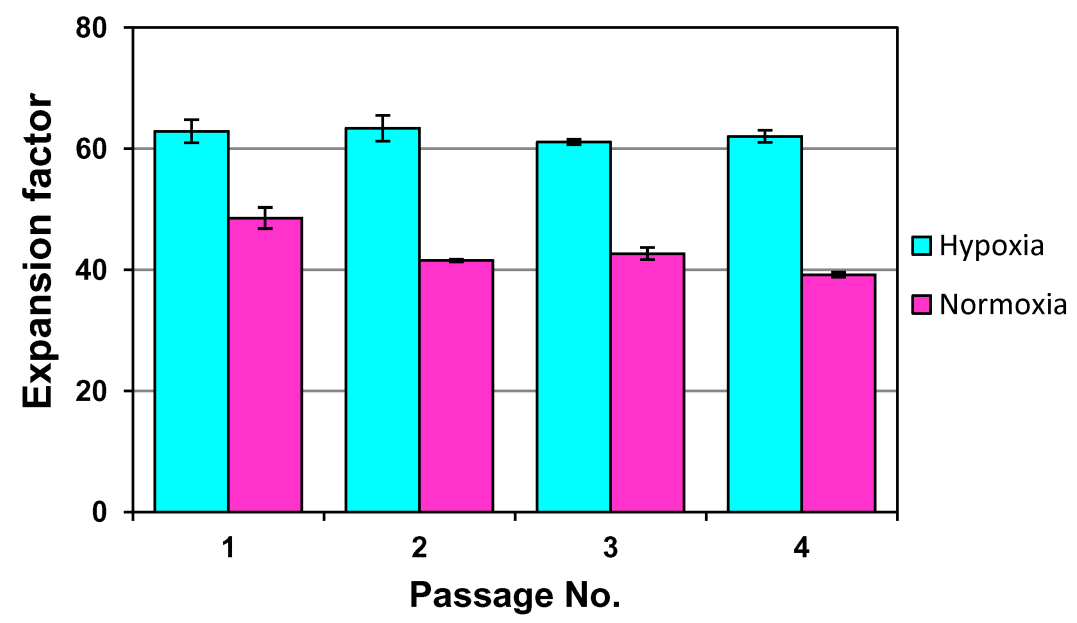

Figure 1. Expansion of mouse adipose tissue MSCs under hypoxia $\left(5 \% \mathrm{O}_{2}\right)$ and normoxia conditions. Cells were seeded at a density of 200 cells $/ \mathrm{cm}^{2}$ in $3.5-\mathrm{cm}$ Petri dishes and grown in MSC growth medium for 4 days followed by the transfer to the next passage. $Y$ axis depicts the magnitude of expansion factor, defined as a ratio of a number of live cells collected at the end of the passage to the number of seeded live cells. Data are presented as mean \pm SD. Cells grown at normoxia show lower growth rates and faster proliferation decline within 4 passages as compared to the cells grown under hypoxia conditions. Importantly, mouse MSCs at normoxia do not proliferate longer than 3-4 weeks whereas those at hypoxia can proliferate for at least 89 weeks before becoming senescent. 


\section{Freezing MSCs}

Note: Perform all manipulations under sterile conditions. The protocol below is intended for freezing 4-5 million cells (8-10 frozen cell samples). If necessary, scale up or down the protocol to accommodate for desired cell numbers.

1. Grow MSCs in six $10-\mathrm{cm}$ Petri dishes under hypoxia conditions until reaching $70 \%$ to $80 \%$ confluency.

2. Detach cells with $1 \mathrm{ml}$ of trypsin solution per dish as described above.

3. Transfer cells to a 15- $\mathrm{ml}$ centrifuge tube, add $5 \mathrm{ml}$ of MSC growth medium, mix with pipette and centrifuge at room temperature for $7 \mathrm{~min}$ at $370 \times \mathrm{g}$.

4. Discard the supernatant and resuspend cells in $4 \mathrm{ml}$ of growth medium.

5. Count the total number of live cells using hemocytometer as described in the step A22 of the Procedure A.

Note: The total number of collected cells is expected to be about $4-5 \times 10^{6}$.

6. Add to the cells $5 \mathrm{ml}$ of fetal calf serum.

7. Add to the cells $1 \mathrm{ml}$ of DMSO. Addition should be performed dropwise to the cells kept under constant agitation (vortexing).

Note: After addition of DMSO, subsequent operations with cells should be performed promptly as high concentrations of DMSO are harmful for cells.

8. Aliquot $1.0 \mathrm{ml}$ of cell suspension into pre-labeled cryotubes (8-10 cryotubes in total).

9. Place the cryotubes into a box lined with cotton wool and transfer to a $-80{ }^{\circ} \mathrm{C}$ freezer for $2-3$ days.

10. Transfer the cryotubes into a liquid nitrogen tank.

D. Thawing MSCs

Note: Perform all manipulations under sterile conditions. The protocol below is designed for thawing one frozen cell sample. If necessary, scale up the protocol to accommodate for desired cell numbers.

1. Remove the cryotube with frozen MSCs from the liquid nitrogen tank, let cell suspension thaw at room temperature.

Note: Make sure cells are completely thawed within 10 min. Hand warming may be used to speed up the process.

2. Add $10 \mathrm{ml}$ of MSC growth medium to the $15-\mathrm{ml}$ centrifuge tube and transfer thawed cells to the same tube.

3. Centrifuge cells at room temperature for $7 \mathrm{~min}$ at $370 \times \mathrm{g}$.

4. Carefully aspirate the supernatant using the pipet, suspend cells in $1 \mathrm{ml}$ of MSC growth medium.

5. Count the total number of live cells using hemocytometer as described in the step A22 of the Procedure A.

Note: The total number of live cells at this stage may vary but usually is about 250-350 thousand per one frozen cell sample.

6. Transfer cells to a 10-cm Petri dish, add MSC growth medium to a final volume of $10 \mathrm{ml}$. 
7. Culture cells in MSC growth medium in a $\mathrm{CO}_{2}$ incubator under hypoxic conditions $\left(5 \% \mathrm{CO}_{2}, 5 \%\right.$ $\mathrm{O}_{2}$ ) until reaching $50 \%$ to $70 \%$ confluency. Change medium every 3 days.

Note: Growth for 5 to 7 days is considered as sufficient for cells to recover and acquire normal physiological state.

\section{Data analysis}

Assessment of quality of cells isolated and expanded using the Procedure A and Procedure B is performed primarily by flow cytometry using antibodies against essential cell surface markers of mouse MSCs, namely positive surface markers CD29, CD44, CD105, and negative markers CD45, CD11b, CD34. After passage 2, the expanded MSC populations are expected to be $98-99 \%$ positive for CD29 and CD44 markers, and about 98-99\% negative for CD11b, CD45 and CD34 markers, whereas they are heterogeneous for expression of CD105 (see Figure 2). Additionally, differentiation into osteocytes, adipocytes and chondrocytes (Sun et al., 2003) may be performed to demonstrate the multilineage differentiation capacity of expanded cell populations. Isolated MSC populations should demonstrate rapid growth, with 12 to $16 \mathrm{~h}$ population doubling times during the first 3-4 weeks in culture.

Note: Depending on conditions of analysis, the percentage of CD34-positive cells may vary and be higher than $1-2 \%$.
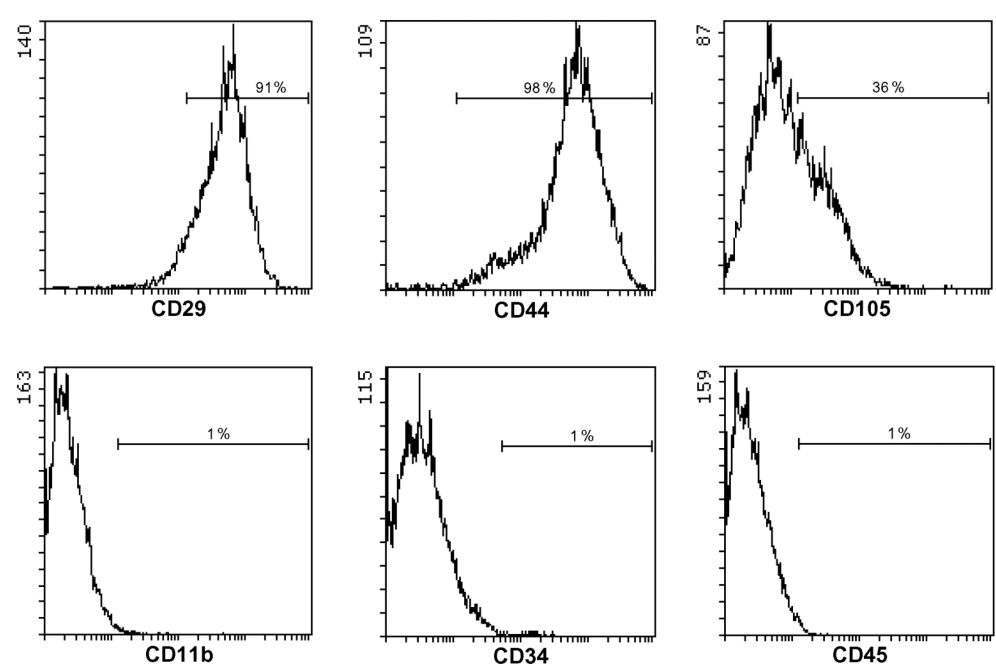

Figure 2. Cell surface phenotype characterization of mouse adipose tissue MSCs by flow cytometry. Cells were stained with propidium iodide (PI), and viable (PI-negative gated) cells were analyzed for binding of fluorescently labeled antibodies against positive markers CD29 and CD44, partially positive marker CD105, weakly positive marker CD34, and negative markers CD11b and CD45. 


\section{$\underline{\text { Notes }}$}

1. For cell isolation, female mice aged about 8 weeks are normally used.

2. In the described protocol, removal of remaining undigested pieces of adipose tissues by filtration through cell strainers is not used as this might lead to cell entrapment and losses. The tissue pieces do not interfere with cell growth and are eventually removed during media changes.

3. Trypsin treatment should not exceed $10 \mathrm{~min}$ as longer exposures may negatively affect cell state.

4. Culture media should be warmed up to $37^{\circ} \mathrm{C}$ prior to work with cells during their expansion.

5. The described culture conditions were empirically determined by us as providing the fastest expansion rates due to significant growth retardation both at low seeding densities and under subconfluent conditions.

6. Under optimal hypoxia culture conditions, murine MSCs can undergo about 80 population doublings before becoming senescent. Spontaneous immortalization or transformation of these cells has never been observed by us under hypoxia growth conditions.

\section{Recipes}

1. DMEM low glucose medium ( $5 \mathrm{~L}$ )

$50 \mathrm{~g}$ DMEM low glucose medium powder

$18.5 \mathrm{~g}$ sodium hydrogen carbonate cell culture grade

Add water to a final volume of $5 \mathrm{~L}$

Sterilize by vacuum filtration

Store at $4{ }^{\circ} \mathrm{C}$

Use within 6 months

2. $\mathrm{MSC}$ isolation medium $(100 \mathrm{ml})$

$93 \mathrm{ml}$ DMEM low glucose medium

$5 \mathrm{ml}$ penicillin-streptomycin (100x)

$2 \mathrm{ml}$ amphotericin B

Combine sterile components under the laminar flow hood

Store at $4{ }^{\circ} \mathrm{C}$

Use within 1 month

3. Collagenase solution (prepare freshly)

Collagenase $12 x \mathrm{~N} \mathrm{mg}$ (where the $\mathrm{N}$ is the weight of adipose tissue)

MSC isolation medium $0.6 \times \mathrm{N} \mathrm{ml}$

Sterilize by filtration through $0.22 \mathrm{~mm}$ filter under laminar flow hood

4. MSC growth medium (1 L)

$880 \mathrm{ml}$ DMEM low glucose medium

$100 \mathrm{ml}$ fetal bovine serum

$10 \mathrm{ml}$ GlutaMax (100x) 
$10 \mathrm{ml}$ penicillin-streptomycin (100x)

Combine sterile components under the laminar flow hood

Store at $4{ }^{\circ} \mathrm{C}$

Use within 1 month

5. 1x phosphate-buffered saline (PBS) pH $7.4(1 \mathrm{~L})$

2 tablets PBS $(10 \mathrm{~g})$

Add water to a final volume of $1 \mathrm{~L}$

Sterilize by autoclaving

Store at room temperature

6. Trypsin solution $(500 \mathrm{ml})$

1 tablet PBS ( $5 \mathrm{~g})$

$100 \mathrm{mg}$ EDTA

$1.25 \mathrm{~g}$ trypsin

Add water to a final volume of $500 \mathrm{ml}$

Dissolve and sterilize by filtration

Store at $4{ }^{\circ} \mathrm{C}$

Use within 6 months

\section{Acknowledgments}

The protocol described herein was adapted with modifications from Andreeva et al. (2015). This work was supported by the grant No. 17-04-02127 from the Russian Foundation for Basic Research and by the program 'Basic research for the development of biomedical technologies' of the Presidium of the Russian Academy of Sciences.

\section{$\underline{\text { References }}$}

1. Andreeva, N. V., Bonartsev, A. P., Zharkova, II, Makhina, T. K., Myshkina, V. L., Kharitonova, E. P., Voinova, V. V., Bonartseva, G. A., Shaitan, K. V. and Belyavskii, A. V. (2015). Culturing of mouse mesenchymal stem cells on Poly-3-Hydroxybutyrate scaffolds. Bull Exp Biol Med 159(4): 567-571.

2. Boregowda, S. V., Krishnappa, V., Chambers, J. W., Lograsso, P. V., Lai, W. T., Ortiz, L. A. and Phinney, D. G. (2012). Atmospheric oxygen inhibits growth and differentiation of marrow-derived mouse mesenchymal stem cells via a p53-dependent mechanism: implications for long-term culture expansion. Stem Cells 30(5): 975-987.

3. Caplan, A. I. (2016). MSCs: The sentinel and safe-guards of injury. J Cell Physiol 231(7): 14131416.

4. Friedenstein, A. J., Gorskaja, J. F. and Kulagina, N. N. (1976). Fibroblast precursors in normal and irradiated mouse hematopoietic organs. Exp Hematol 4(5): 267-274. 
5. Krishnappa, V., Boregowda, S. V. and Phinney, D. G. (2013). The peculiar biology of mouse mesenchymal stromal cells--oxygen is the key. Cytotherapy 15(5): 536-541.

6. Murray, I. R., West, C. C., Hardy, W. R., James, A. W., Park, T. S., Nguyen, A., Tawonsawatruk, T., Lazzari, L., Soo, C. and Peault, B. (2014). Natural history of mesenchymal stem cells, from vessel walls to culture vessels. Cell Mol Life Sci 71(8): 1353-1374.

7. Phinney, D. G. and Sensebe, L. (2013). Mesenchymal stromal cells: misconceptions and evolving concepts. Cytotherapy 15(2): 140-145.

8. Prockop, D. J. (2013). Concise review: two negative feedback loops place mesenchymal stem/stromal cells at the center of early requlators of inflammation. Stem Cells 31(10): $2042-$ 2046.

9. Sun, S., Guo, Z., Xiao, X., Liu, B., Liu, X., Tang, P. H. and Mao, N. (2003). Isolation of mouse marrow mesenchymal progenitors by a novel and reliable method. Stem Cells 21(5): 527-535. 